\title{
OVERDOSE BY SODIUM PHOSPHATE DEXAMETHASONE
}

\section{CASE REPORT}

- A 51-year-old woman (75,600 Kg - 1,57 m), ASA II (centrolobular breast cancer, tamoxifen treatment), posted for right POSTMASTECTOMY FREE FLAP.

- INDUCTION : fentanyl (2 mcg/Kg), propofol $(2.5 \mathrm{mg} / \mathrm{kg})$, rocuronium $(0.6 \mathrm{mg} / \mathrm{Kg})$,

- MAINTENANCE : remifentanil $(0.14 \mu \mathrm{g} / \mathrm{Kg} / \mathrm{ml})$, sevoflurane $2 \%$ and BRC $0.06 \mathrm{mg} / \mathrm{kg} / \mathrm{h}$. Right jugular central line guided by ultrasound.

Thirty minutes after begining, 200 mgs of dexamethasone phosphate (Fortecortin ${ }^{\circledR}$ ) were accidentally administered, being notified 5 minutes after. Arterial and venous hourly gasometry only showed mild hypocalcemia. Crystalloids and furosemide (20mg) were administered.

Total surgical time: 6 hours.

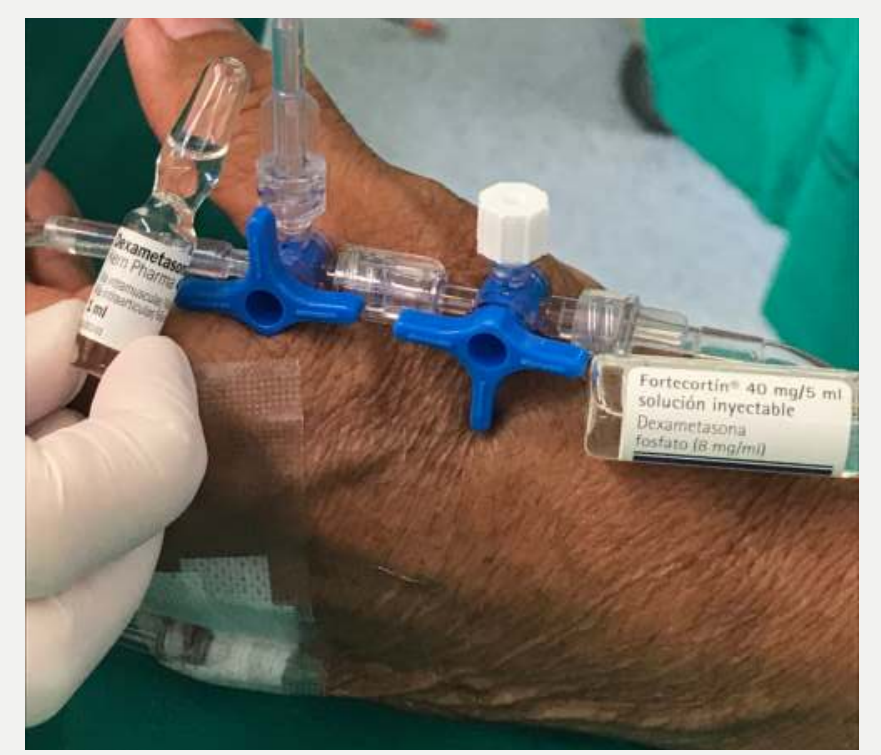

- EVOLUTION : 90 minutes postsurgery the patient was stuporous (responding only to painful stimuli), Glasgow 4 points, without airway reflexes. She was extubated in UCPA two hours later, at that moment responding to both verbal and tactile stimuli but being very drowsy and bradypsychic. Brain CT scan was normal. For the next 48 hours she remained in UCPA, sleepy, with normal cortisol and ACTH levels. Persistent nystagmus was observed for 3 days. Seven days after surgery, she presented loss of consciousness and rigidity when removing the central line; MYOCLONUS and ALTERNATING HEMIPLEGIA appeared but CT and EEG showed any patological findings. MRI showed diffuse alteration of the cortical signal. A diagnosis of reversible posterior encephalopathy was considered. 5 days after this episode mioclonus and alternating hemiplegias persisted without any injuries to justify them so the patient was discharged and sent for psychiatric evaluation with a final diagnosis of CONVERSIVE DISORDER.

\section{DISCUSSION}

$\checkmark$ Meta searchers (Tripdatabase, Epistemonikos, UpToDate) confirm that there are few or no reported cases of accidental acute overdose of dexamethasone in patients undergoing long-time surgeries.

$\checkmark$ Dexamethasone is a glucocorticoid with great anti-inflammatory properties, equivalent to $25-30$ times that obtained with cortisone. It is mainly based on the inhibition of fibrin deposits, capillary dilation and inhibition of the migration of leukocytes to the inflamed area.

$\checkmark$ In our case, the patient presented hydroelectrolytic alterations (hypocalcemia), as well as disorders in the CNS reflected in the delay in awakening and subsequent development of a clinical picture compatible with a conversion disorder vs a reversible posterior encephalopathy. 